\title{
University
}

Bain, D. (2019) Why take painkillers? Nô̂s, 53(2), pp. 462-490.

There may be differences between this version and the published version. You are advised to consult the publisher's version if you wish to cite from it.

This is the peer reviewed version of the following article Bain, D. (2019) Why take painkillers? Nô̂s, 53(2), pp. 462-490, which has been published in final form at http://dx.doi.org/10.1111/nous.12228. This article may be used for non-commercial purposes in accordance with Wiley Terms and Conditions for Self-Archiving.

http://eprints.gla.ac.uk/137527/

Deposited on: 7 November 2017

Enlighten - Research publications by members of the University of Glasgow http://eprints.gla.ac.uk 


\section{Why Take Painkillers?}

Forthcoming in Noûs 2017. For final version, see

http://onlinelibrary.wiley.com/journal/10.1111/(ISSN)1468-0068/earlyview

\section{David Bain, University of Glasgow}

Accounts of the nature of unpleasant pain have proliferated over the past decade, but there has been little systematic investigation of which of them can accommodate its badness. This paper is such a study. In its sights are two targets: those who deny the noninstrumental badness of pain's unpleasantness; and those who argue that this badness cannot be accommodated by the view - which I and others have advocated-that unpleasant pains are interoceptive experiences with evaluative content. Against the former, I argue that pain's unpleasantness does indeed have non-instrumental badness; against the latter, I argue both that my critics' own desire-theoretic accounts of pain's unpleasantness cannot accommodate such badness, and that my evaluativist view can-either by appealing to "anti-unpleasantness" desires or by exploiting pain's perceptuality.

\section{Two Conditions}

Suppose you're asked why you took a painkiller. An obvious reply is: "I was in pain". Pressed to say more, you might elaborate: "My pain was unpleasant." And, if your interlocutor still isn't satisfied, you might add: "Unpleasant pain is a bad state to be in." This last claim is surely true. We don't take painkillers to prevent bodily damage, but to prevent or reduce unpleasant pain. And this, surely, is a good reason to take them. Similarly, there is good reason to pity people in unpleasant pain and to condemn its gratuitous infliction on others. For, quite simply, unpleasant pain is pro tanto bad for its subjects. But can current accounts of the nature of unpleasant pain accommodate that normative truth? That is our topic.
I specified "unpleasant pain". So I am not talking about the pains undergone by pain asymbolics or any other non-unpleasant pains. ${ }^{1} \mathrm{I}$ also said "pro tanto". So my claim shouldn't be doubted on the basis that unpleasant pains are good for you. They are indeed. They prevent damage, aid recovery, and contribute to learning. People incapable of pain die young. Moreover, unpleasant pains can cause pleasure and cultivate and enable the exercise of virtues. ${ }^{2}$ But, for all that, an unpleasant pain is still bad for you, even if only slightly, even if only pro tanto, even if (in other words) its badness is outweighed-perhaps far outweighed-by its benefits.

We can go further: your unpleasant pain is not only bad for you, but bad for you non-instrumentally-that is, independently of its bad consequences. Or so I shall argue. Hence we can distinguish among three loci of disvalue when a rotten tooth of yours is aching. Upstream of your pain is the damage in your tooth, which is bad for you. Downstream are your pain's negative emotional consequences-for instance anxiety and anger-which are bad for you. And, nestled between the damage and those consequences, is the pain's unpleasantness, which is also-and independently - bad for you.

This idea, that unpleasant pain is non-instrumentally bad for a subject, underlies the following:

\section{Normative condition}

Being in unpleasant pain could consist in being in state $\phi$ only if being in state $\phi$ is, in the relevant cases, noninstrumentally bad for its subject.

That condition, I take it, must be met by parties to what we might call the "affect debate" - the currently vigorous debate about the nature of pain's unpleasantness. Now, many also claim that parties to that debate must meet a second condition, one arising from taking "Why did you take a painkiller?" as a demand not for a justification (as above) but for a motivation. For it is thought that what motivates a subject in pain to take

On pain asymbolia, see Grahek 2007 and Bain 2014

${ }^{2}$ On pleasure, see Bastian and Leknes 2014; on virtue, see Brady forthcoming-b. 
a painkiller is the unpleasantness of her pain itself. ${ }^{3}$ Unpleasant pain, the idea goes, is in this sense self-eliminating. Hence the following condition:

\section{Self-elimination condition}

Being in unpleasant pain could consist in being in state $\phi$ only if being in state $\phi$ could, in the relevant cases, itself motivate actions aimed at minimising the subject's unpleasant pain.

Now, in the present paper I ask how these two requirements-the normative and self-elimination conditions-bear on the affect debate. In particular, I focus on the charge-made recently by Murat Aydede, Michael Brady, Matthew Fulkerson, and Hilla Jacobson-that evaluativism, a view of mine according to which pain's unpleasantness is to be explained in terms of evaluative perception, cannot handle the two conditions. ${ }^{4}$ I proceed as follows. In §2, I formulate evaluativism and explain the charge. In $\S 3$, I argue that the charge cannot be avoided simply by denying the normative condition. And in the remainder of the paper, I respond to the charge: first, by denying that my critics' own desire-theoretic accounts of unpleasantness meet the normative condition (§§4-6) and, second, by showing how evaluativism can meet it - and how, moreover, it can handle, if not meet, the self-elimination condition too (§§7$8)$.

\section{Evaluativism and Two Objections}

What is it to be in pain? And in virtue of what is a pain unpleasant? My evaluativist answer (also given by Bennett Helm, Brian Cutter, and Michael Tye) is this: 5

${ }^{3}$ See for example Aydede and Fulkerson's "e-Motivation" (forthcoming).

${ }^{4}$ For the charge, see Aydede and Fulkerson in review, Brady 2015, Jacobson 2013 and in review, and my own 2013.

${ }^{5}$ See Bain 2013 and 2017, Helm 2002, and Cutter and Tye 2011.

\section{Evaluativism}

1. Your being in pain consists in your undergoing an interoceptive experience (the pain) that represents bodily damage.

2. Your pain's being unpleasant consists in its additionally representing that damage as bad for you.

Contrast this with the once-orthodox idea that, while visual and other perceptual experiences are intentional or content-bearing, pains and other bodily sensations are "blank", sometimes enabling one to infer how one's own body is, but not themselves endowed with personal-level content (McGinn 1982; Rorty 1980). Claim (1) breaks with that tradition. It says that pains are content-bearing perceptual experiences, in particular interoceptive experiences - in which you are aware of your own body "from the inside" - that represent, correctly or incorrectly, that a body part of yours is in a given extramental state, for instance (as above) being damaged or (on other versions of the view) being under threat of damage or undergoing some kind of "disturbance". ${ }^{6}$ However, what sets evaluativism apart from many of its current rivals is not claim (1), which current rivals tend to share, but claim (2), which explains your pain's unpleasantness in terms of its evaluative content-again, its representing something more than that the given body part is damaged, namely that the damage is bad for you. Notice, crucially, that the represented badness on this view is not the badness of the unpleasant pain, but rather the badness of a bodily condition. So the idea, again, is that it is by dint of representing the badness-for-you of some bodily damage (say) that your pain is unpleasant, and it is in turn by dint of your pain's being unpleasant that your pain is bad-for-you.

And here the trouble starts. For mental states rarely instantiate the properties they represent. A visual experience of a red cube is not itself a red cube. So why, my four critics ask, think that interoceptive experiences representing conditions of your body as bad for you are themselves bad for you (non-instrumentally)? And if they are not, the objection goes, then evaluativism violates the normative condition: it

${ }^{6}$ Although I suspect the version invoking threat is preferable (Bain 2017), I will for simplicity stick with the more typical damage-invoking version in this paper. 
explains something that is non-instrumentally bad for you (namely, your pain's unpleasantness) in terms of something that is not (namely, your experience's representing a state as bad for you).

Recall your rotten tooth. For all that has been said, evaluativists can accommodate the badness-for-you of two things: your tooth's rotten state, and the emotional consequences of the unpleasant pain it causes. But evaluativism (the worry goes) cannot accommodate the badness-foryou of the pain's unpleasantness itself. For evaluativism says that the unpleasantness consists in the pain representing that your tooth's state is bad for you, and what is non-instrumentally bad about that?

Call this the normative objection. It is often elaborated in terms of two non-pain cases. The first is evaluative belief (Brady 2015, Jacobson in review). Suppose you come to believe, correctly, that you are seriously ill and that your being so is a bad situation for you to be in. Independently of its consequences, does that belief make your situation worse? Surely not, the critics insist. And, they insist, just as believing that things are bad for you is not non-instrumentally bad for you, so experiencing things to be bad for you is not non-instrumentally bad for you.

The other case is evaluative testimony (Jacobson 2013 and in review). For evaluativists, it is assumed, construe unpleasant pains as episodes in which your pain system conveys to you bad news about your body. But why should bad news being conveyed to you itself be bad for you, independently of the truth of the news or the effects of its being conveyed? Surely what is bad about bad news is whatever the news concerns, and the effects of hearing it, not the mere fact of having it conveyed. If evaluativism were true, the worry goes, then taking a painkiller just to eliminate your pain's unpleasantness (as against its consequences) would be irrational. But it isn't. Hence the normative objection is sometimes known as the messenger-shooting objection.

Turning to the self-elimination condition, the critics say that evaluativism violates it too (Aydede and Fulkerson in review) Evaluativists tend to claim that experiences representing damaged bodily states as bad for you can themselves motivate you (pro tanto) to act to eliminate those states (Helm 2002, Bain 2013 and In review). But, even if true, this fails to explain how your unpleasant pain motivates the taking of painkillers or other behaviour aimed at minimising not damaged states, but your unpleasant pain itself. Again, for evaluativists, pain's unpleasantness is a first-order state, representing the extra-mental world; but how could such a state motivate second-order behaviour, aimed at minimising the mental state of unpleasant pain?

In sum, the objection is that evaluativism violates both the normative and self-elimination conditions. For now, I shall set aside the self-elimination condition. Let us ask, then: how might the normative condition be handled?

\section{Strategy 1: Instrumentalism}

Might we just deny the normative condition? Might we insist that pains are bad only in virtue of their bad consequences? This approach-call it instrumentalism or strategy 1 -has recently been defended by Manolo Martínez (2015). For him, the key to pain's badness is its motivationality. He thinks your pain motivates you (pro tanto) to minimise the damage it represents, which he models in terms of its inserting into your "action plan"-your continually updated ranking of goals-the following goal: to minimise the represented state of bodily damage as soon as possible. Thereby, your pain demotes all goals ranked below the new one. Presumably, what you actually do might not be affected. You might take the stroll you wanted to despite the pain in your ankle. But your pain still affects your ranking, perhaps changing what you would have done had your desire for a stroll been weaker. And, for Martínez, it is in virtue of this sort of interference with one's action plans-"intrusiveness", as I shall call itthat unpleasant pains are bad. ${ }^{7}$ Why are intrusive effects bad? Martínez doesn't say, but Colin Klein (who advances a similar view) does. ${ }^{8}$ Intrusiveness, he says, compromises your agency (Klein 2015b).

Now, Martínez is not an evaluativist, but an imperativist. He claims that pains are unpleasant and motivational by dint of being experiential commands. But notice my version of evaluativism shares with imperativism the idea that unpleasant pains are inherently motivational. They are, I think, motivational by dint of their evaluative

"I have set aside Martínez's talk of "spammy" pains - pains that demote "reasonable" goals for goals that are "unfulfillable or misguided" (2015: 2270)-since I take it Martinez thinks that even non-spammy pains have intrusive effects and are thereby pro tanto bad.

${ }^{8} \mathrm{Or}$ at least his view seems similar. It is sometimes unclear whether Klein is explaining what makes pains unpleasant or what makes their unpleasantness bad (2015b: ch. 14). 
content. Hence it would be good news for me if Martínez's instrumentalism were plausible. For I too might then invoke pain's intrusive effects and deny the normative condition. Unfortunately, however, Martínez's instrumentalism is not plausible.

One problem is that intrusiveness is not limited to pain or even to unpleasant experience in general. Non-unpleasant urges-not to step on the cracks in the pavement, for instance-can also be intrusive. So can pleasures. Hence Martínez looks committed to saying that a pleasurable experience too inserts various goals into your action plan: to prolong that experience, perhaps, or to prolong the condition it represents. Yet surely the pleasurable experience is not thereby bad for you, not even pro tanto. And even were it, there is surely a profoundly important, different way in which your unpleasant experiences, for instance your pains, are bad for you.

Relatedly, one of the things that is bad for you about your pain is something that can be profoundly hard to tolerate, even when the pain is only momentary. Whatever this bad-making feature is, it is surely not intrusiveness. For suppose, suffering intense but brief agony under torture, you cry "I can't stand this". What is it that you so profoundly cannot stand? The forced re-ordering of your goals? There may be cases in which that would be plausible, if for instance chronic pain had interfered for many years with how you live. But it is not plausible in the torture case, in which the pain-and its re-ordering of your goals-is fleeting. What, then, is it that you cannot stand? The feel of your unpleasant pain itself, I suggest; again, the awful way things seem to you when in such pain. ${ }^{9}$

Parting with Martínez, other instrumentalists might appeal to consequences other than pain's intrusiveness, perhaps most promisingly to downstream negative emotions such as anxiety and anger. These, after all, can be hard to stand. But notice that one of the things we worry about when in unpleasant pain is, precisely, the unpleasant pain itself: that it might not stop or might worsen. And it is quite unclear that instrumentalists who explain the badness of pain entirely in terms of

${ }^{9}$ Intolerability requires more attention than it has received. One question is whether finding something intolerable is more than having a strong intrinsic desire that it not occur. Even if not, my point stands, since what you so strongly want the non-occurrence of when tortured is surely not the re-ordering of your priorities. emotional effects can make sense of that worry. Suppose, under torture, you somehow know that you will not betray any secrets or sustain any bodily damage. And suppose the only negative emotion you undergo during the torture is a worry you would express thus: "This pain might get even worse". Surely that is not a worry about itself: a worry that this very worry will get worse. Might it instead be a worry that you will come to experience new worries? That too is implausible. You might have good reason to doubt that the torture will induce new worries-or other negative emotions - and yet you might still worry that the pain will get worse. Instead, I suggest, your worry is a worry that the feeling of your pain's unpleasantness itself will get worse, and worse in a way not exhausted by its causing or intensifying either this very worry or any other emotional effects. But our instrumentalist, who denies that the feeling of your pain's unpleasantness is itself non-instrumentally bad, cannot make sense of that.

This instrumentalist must also explain what is bad about the negative emotions invoked. Plausibly, what is bad is their unpleasantness. But how is our instrumentalist to explain the badness of that? Appealing only to intrusiveness is no more promising here than in the case of pain's unpleasantness. So, here-or soon, as the causal chain of negative feelings unfolds - the instrumentalist looks bound to appeal to a feeling that is potentially intolerable and bad for its subject non-instrumentally. And why, we might wonder, is imputing non-instrumental disvalue to the feeling downstream more plausible than imputing it to pain's unpleasantness at the outset?

Finally, whether it appeals to intrusiveness or emotional suffering, instrumentalism faces the following challenge. After a long and happy life, Stan regards with equanimity the painless death he knows is coming in the next few minutes, which he is spending walking bare-foot along a beach at sunset, awaiting his favourite moment when the sun slips below the horizon. Here are two ways Stan's story might unfold. At world 1, he steps on a sharp stone in the sand. This causes a fleeting but intense pain. But it does not cause bodily damage. Nor is he annoyed or upset or made anxious by the brief pain. Yet it does direct his attention to his foot, resulting in his missing the sunset's final moment. At world 2, by contrast, the stone is a metre to the left, so Stan doesn't step on it and does not feel any pain. But he does hear a rustle in the bushes. He is not upset 
or annoyed or made anxious by this auditory experience. Yet it does direct his attention to the bushes, resulting in his missing (as at world 1) the sunset's final moment. Now, neither world is very bad for Stan. Even so, I suggest that, all else equal, world 1 (in which what causes Stan to miss his favourite moment is a pain) is slightly worse-or less good-for him than world 2 (in which what causes him to miss his favourite moment is an experience of rustling). But how to explain that? Not in terms of any damage the stone causes at world 1, since it doesn't. Nor in terms of any unpleasant emotional effects his pain causes, since it doesn't. Nor in terms of his missing the sunset's final moment, since that happens at both worlds. Nor in terms of any other intrusive effects of his pain, since his pain is no more intrusive than his auditory experience. Rather, I suggest world 1 is worse because of the non-instrumental badness of the unpleasantness of the pain that Stan feels when he steps on the stone.

In sum, we cannot save evaluativism (or imperativism) by simply denying the normative condition. So what should we do? In what follows, I take a dual approach. In $\S \S 4-6$, I question whether those who deny that evaluativism meets the normative condition - "my critics" - can meet it themselves. In §§7-8, I argue that evaluativism actually can meet the condition, using either of two strategies.

\section{SOD and Two Desire-Based Strategies}

The currently dominant approach to the normative condition is to explain pain's unpleasantness in terms not of evaluative or imperative content, but rather desires, and then to invoke those very same desires to explain the badness of its unpleasantness. This is the approach taken by my four critics: Aydede, Brady, Fulkerson, and Jacobson. ${ }^{10}$ It comes in numerous forms, but I will argue they all fail. I begin, in this section, with the second-order desire view (SOD) and two normative strategies its adherents might advance. follows: ${ }^{11}$

Embraced by many, including Brady, SOD can be formulated as

${ }^{10}$ See Aydede 2014 and Aydede and Fulkerson forthcoming; Brady 2015, forthcoming-a, and forthcoming-b; and Jacobson in review. On this categorisation of Aydede and Fulkerson's view, see note 16 below.

${ }^{11}$ See Armstrong 1962, Brady 2015, Heathwood 2007. For more references, see Bain 2013.

\section{Second-order desire view (SOD)}

1. Your being in pain consists in your undergoing an interoceptive experience (the pain) that represents bodily damage.

2. Your pain's being unpleasant consists in your having an intrinsic desire that it (the pain) not occur.

On this formulation, SOD theorists agree with evaluativists about what makes an experience a pain-its representing bodily damage-but disagree about what makes it unpleasant. ${ }^{12}$ It counts as unpleasant, they think, not in virtue of possessing evaluative content, but in virtue of your intrinsically wanting its non-occurrence. As I'll put it, your pain is unpleasant by dint of your having the right negative, second-order desire, namely an anti-pain desire (where I use the terms "anti-x desire", "negative desire", and "desire for not- $x$ " for an intrinsic desire for $x$ not to occur, and "second-order desire" for desires directed at one's own mental states).

But how might anti-pain desires explain the badness of unpleasantness? The core idea is that undergoing an experience you want not to be undergoing - as SOD entails you are when in unpleasant painis a non-instrumentally bad state to be in. But notice (as it often isn't) that there is a choice here between two different normative strategies:

\section{Strategy 2: the desire strategy}

Explain the badness-for-you of your pain's unpleasantness in terms of two ideas: (a) the unpleasantness being constituted by an anti-pain desire; (b) narrow-scope Humeanism: that if $S$ has an anti- $x$ desire, then it is pro tanto non-instrumentally bad for $S$ that $x$ obtain.

${ }^{12}$ A few don't accept (1), but (2) is my focus here. 


\section{Strategy 3: the desire-frustration strategy}

Explain the badness-for-you of your pain's unpleasantness in terms of two ideas: (a) the unpleasantness being constituted by an anti-pain desire; and (b) wide-scope Humeanism: that it is pro tanto non-instrumentally bad for $S$ that $\underline{S \text { have an anti- } x \text { desire }}$ while $x$ obtains.

The two strategies differ in respect of narrow- and wide-scope Humeanism. To appreciate the contrast, suppose your mother is ill and you want her not to be. What is bad for you? According to narrow-scope Humeanism: your mother's being ill. According to wide-scope Humeanism: the conjunctive state of affairs of your mother's being ill while you want her not to be. Again, according to narrow-scope Humeanism, there is a justifying reason for you to eliminate your mother's illness, whereas according to wide-scope Humeanism there is a justifying reason for you either to eliminate her illness or to eliminate your desire for her not to be ill-by, say, taking an anti-desire pill. In other words: narrow-scope Humeanism makes your desire a ground of your mother's illness's being bad for you, whereas wide-scope Humeanism makes it a constituent of the state of affairs that is bad for you. So, returning to antipain desires and the badness of unpleasant pain, strategy 2 in SOD's hands entails the desire-dependent badness-for-you of your anti-pain desires' objects-your pains-whereas strategy 3 entails the badness-foryou of your anti-pain desires' frustration. The question is: does either strategy work ${ }^{13}$

${ }_{13}$ The distinction between these two varieties of Humeanism is akin to scope distinctions regarding what you have reason to do, or ought to do, and also what you have reason to judge. On the former,

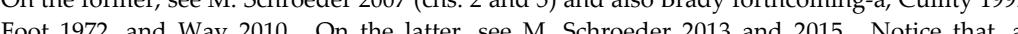
Foot 1972, and Way 2010. On the latter, see M. Schroeder 2013 and 2015 . Notice that, formulated, narrow-scope Humeanism doesn't make it a necessary condition of $x^{\prime}$ s being noninstrumentally bad for you that you have an anti- $x$ desire; nor does wide-scope Humeanism say that desire-frustration is the only thing that is non-instrumentally bad for a subject. Notice too that there are restricted versions of Humeanism on which only some desires (e.g. those you would have in certain idealised conditions) entail a thing's goodness or badness for you (or are such that their frustration is non-instrumentally bad for you). See for instance Smith 1994 and Railton 2003. Such restrictions won't matter for our purposes.
Here are two worries about the desire strategy, at least in SOD's hands. First, while Humeanism of either stripe is controversial, we might especially balk at the wide-scope version, in particular at the idea that your intrinsic desire for your mother not to be ill together with the fact that she is ill constitutes a non-instrumental reason on which you could act not only by taking steps to make her better but also by popping an anti-desire pill. Why balk at that? Well, for one thing, when you act to make her better, that you want her not to be ill doesn't enter into the content of your motivations. Relatedly, what you take to be your reason for action is surely that she is ill, not that she is ill and you want her not to be. For another thing, wide-scope Humeanism arguably conflicts with the following, attractive reading of the prevalent thought that desires contrast with beliefs in having a world-to-mind direction of fit: that in cases of world-desire mismatch-contrast world-belief mismatch-one should change the world to fit one's desire rather than one's desire to fit the world (which is not, notice, to deny that we sometimes have instrumental reasons to rid ourselves of desires we believe not to be easily satisfiable).

Now, getting to the bottom of these general issues is beyond this paper's scope, but notice there is also a more specific worry about the desire-frustration strategy in SOD's hands, namely that it appears to violate the intuition I used against Martínez: that what is bad for you when in unpleasant pain is how your unpleasant pain feels to you. For the desire-frustration strategy says that what is bad for you is your anti-pain desire's frustration. Yet a desire's frustration is not itself a feeling. True, there is such a thing as feeling frustrated, but what the desire-frustration strategy says is bad for you is not that or any other feeling, but rather frustration in the semantic sense, that is the non-satisfaction of a desire. And one's desires can be frustrated in that sense even when one is unconscious and not feeling anything at all. ${ }^{14}$

In this respect, the desire strategy might seem to improve on the desire-frustration strategy. For if the anti-pain desire that SOD invokes is construed as a desire for the feel of your pain not to occur, then it is

${ }^{14}$ Another worry about the desire-frustration strategy in SOD's hands is that your anti-pain desire is arguably not frustrated in a case in which it is a desire had at noon for the immediate cessation of a pain that indeed ceases a millisecond after noon. But this worry might be addressed by invoking (as my formulation does) desires not that the pain stop, but that it not be occurring now. 
precisely that feel that the desire strategy says is bad for you. Nonetheless, I fear the desire strategy also mislocates the badness of your unpleasant pain. True, it locates it in a feeling-but the wrong feeling. For notice that SOD invokes anti-pain and not anti-unpleasantness desires. Hence, in SOD's hands, what the strategy makes non-instrumentally bad for you is your pain per se, not your pain's unpleasantness. Yet, I suggest, really it is your pain's unpleasantness that is non-instrumentally bad for you.

Care is needed here. The point is not that SOD theorists who pursue the desire strategy are committed to the implausible idea that nonunpleasant pains (for instance, asymbolic or morphine pains) are noninstrumentally bad for their subjects. They needn't say that since they will claim that the ground of the non-instrumental badness of pain per se (namely, an anti-pain desire) is absent in non-unpleasant cases. But, even so, they are committed to saying that, when a pain is unpleasant, what is non-instrumentally bad for the subject is the pain per se and not its unpleasantness. And this too, I think, is implausible.

Suppose, in agony, you howl "I want the pain to stop". Despite your use of the word "pain", I claim the following: your howl-if it gave voice to an intrinsic desire at all-gave voice to an anti-unpleasantness and not an anti-pain desire. To see this, suppose that I respond to your cry by giving you morphine, which entirely eliminates (as morphine sometimes does) the unpleasantness but not the pain. Despite the persistence of the pain, wouldn't you say that I had satisfied the desire you voiced? Again, in giving you morphine and eliminating the unpleasantness, surely I have not merely eliminated the desire you voiced (as in a case where I terminate rather than satisfy your desire that your mother not be ill) but have given you just what you said-or, better, meant-you wanted. So far as your intrinsic desires regarding your unpleasant pain go, indeed, I have given you everything you wanted.

We can come at the same point from the other direction. Suppose I respond to your cry instead with an anti-pain drug: a drug that eliminates the pain by somehow substituting for it another sensationperhaps an itch-that is precisely as unpleasant as the pain was. In this case I suspect you would complain that I had misunderstood what your howl of "I want the pain to stop" was getting at. You would, I suggest, complain that I hadn't satisfied any desires of yours. For, again, what you wanted was for the unpleasantness to stop.

In sum, I think it doubtful that that we typically have anti-pain as against anti-unpleasantness desires. And since our negative intrinsic desires at least reflect what we take to be non-instrumentally bad, this is evidence that pain per se is not non-instrumentally bad for a subject. Yet, in SOD's hands, the desire strategy says it is.

That we don't typically have anti-pain desires, notice, also poses a more direct problem than the mislocation of badness. And it is a problem facing not just the desire strategy in SOD's hands, but the desirefrustration strategy too. For, in SOD's hands, both strategies appeal to anti-pain desires to explain why unpleasant pains are typically bad: the desire strategy appeals to their normative implications for their objects, the desire-frustration strategy to the normative significance of their frustration. Yet neither appeal is plausible if anti-pain desires are desires we typically lack. ${ }^{15}$

In SOD's hands, then, both the desire and desire-frustration strategies are problematic. So let us now turn to an alternative to SOD, and ask whether it can make better use of desire-based normative strategies.

\section{FOD: the Desire and Desire-Frustration Strategies}

In recent years, first-order accounts of pain's unpleasantness have challenged SOD's dominance. These include imperativism, evaluativism, and the first-order desire view (FOD). FOD, the last of these, numbers among its adherents my three remaining critics: Aydede, Fulkerson, and Jacobson. It can also seem an especially attractive alternative to SOD. Eschewing anti-pain desires but not desire altogether, it avoids some of SOD's problems while looking able to exploit the SOD theorist's putative insight: that the normative status of pain's unpleasantness might be explained via the normative power of desire. ${ }^{16}$ In this section and the next,

${ }_{15} \mathrm{SOD}$ theorists might respond by explaining pain's unpleasantness in terms of antiunpleasantness desires instead. But that would require saying, unattractively, that a given desire might be both directed at and constitutive of a given instance of unpleasantness.

${ }^{16}$ See Aydede 2014, Aydede and Fulkerson forthcoming, and Jacobson 2014 and in review. As psychofunctionalists, Aydede and Fulkerson say that a pain's unpleasantness consists in the 
however, I argue that this appearance is illusory, that the desire-based normative strategies that failed for SOD also fail for FOD, and that a third and final desire-based strategy fails too.

FOD claims the following:

\section{First-order desire view (FOD)}

1. Your being in pain consists in your undergoing an interoceptive experience (the pain) that represents bodily damage.

2. Your pain being unpleasant consists in your having an experience-based intrinsic desire that that bodily damage (represented by the pain) not obtain.

For FOD, then, what makes a pain unpleasant is not an anti-pain desire, but an anti-damage desire, and (I take it) not a general anti-damage desire, but a desire for the given instance of damage represented by the pain not to be occurring, perhaps a desire whose reference is fixed by the pain to that instance in the manner of a demonstrative thought-so a desire, again, for that damage not to occur. ${ }^{17}$ Now, for us, the question is: how might this desire explain your unpleasant pain's badness? In particular, might either of the desire-based strategies that failed for SOD work for FOD?

The desire strategy doesn't. Its idea is that if $S$ has an anti- $x$ desire then $x^{\prime}$ s obtaining is non-instrumentally bad for $S$. But in the hands of FOD, which invokes anti-damage rather than anti-pain desires, this could at best explain the badness of instances of bodily damage, which is not

"negative m-processing" of the information registered by the pain, which information concern pain experience's involving such processing with its involving a "phenomenologically salien experiential desire", one to the effect that the represented disorder "cease or go away". Admittedly, they distinguish the idea of such "phen-desires" from the "ordinary" concept of desire, but they are clear that phen-desires are "desire-like" and their idea that "phen-desire frustration ... is itself bad" derives whatever plausibility it has from the kinship between phendesires and ordinary desires. See also note 27 below.

${ }^{17}$ This is one way of capturing the experientiality that FOD theorists tend to attribute to their unpleasantness-constituting desires (see note 16 above). For doubts about the normative relevance of any conception of a desire's experientiality, see $\S 6$ below. what was supposed to be explained. The explanandum is rather the badness of unpleasant pain.

For FOD theorists, the desire-frustration strategy might seem more promising. For it invokes not the badness of an anti-damage desire's object, but the badness of an anti-damage desire's frustration. And indeed this, at times, appears to be the strategy my three remaining critics' have in mind. Aydede and Fulkerson say, for instance, that what is bad for you about an unpleasant pain is that it consists in a damage-representing experience being accompanied by a frustrated "desire-like" state focused on that damage, adding that desire-frustration "is itself bad" (forthcoming). ${ }^{18}$ And Jacobson speaks of your pain's "painfulness" being "constituted by a (frustrated) conative attitude", and she goes on to give an account of the badness of such frustration (in review). But I fear that, for FOD, the desire-frustration strategy fails as surely as the desire strategy did.

For one thing, some of our earlier worries recur: namely, that desire-frustration is not a feeling, and that wide-scope Humeanism is highly controversial. But there is also a more straightforward difficulty: not all cases of non-instrumentally bad pains involve the frustration of anti-damage desires. Consider, for example:

Pain Illusion. You have an intensely unpleasant pain in your foot. But there is no damage in that foot. Rather, the unpleasant pain is illusory, caused by some central neuropathy.

In this case, the desire-frustration strategy in FOD's hands says the following: your pain consists in your interoceptively representing your foot as damaged; its unpleasantness consists in your wanting that damage not to occur; and the badness of its unpleasantness consists in that desire being frustrated. But notice: that desire isn't frustrated! You want your foot not to be damaged and it isn't. ${ }^{19}$

${ }^{18}$ Actually, they talk of disturbance- rather than damage-representation, but this difference doesn't matter for our purposes. On "desire-like" states, see note 16 above.

19 There is prima facie no parallel difficulty for SOD. For cases in which it falsely seems to one that one is undergoing an experience whose non-occurrence one wants are harder to imagine. 
It might be replied that illusory pains, representing damage where there is none, are not unpleasant (perhaps because unpleasantnessconstituting anti-damage desires exist only when they successfully refer). But if pains represent bodily damage or disturbances, then pain illusions are widespread, and it simply beggars belief to say that none of the illusory cases is unpleasant. FOD theorists might alternatively claim that illusory pains, even if unpleasant, are not non-instrumentally bad for you. But this too beggars belief. Consider a veridical unpleasant pain that is non-instrumentally bad for you. Suppose now that God eliminates the damage but tweaks your brain so that your pain experience persists, phenomenally unchanged. In this case, God has eliminated your pain's veridicality but not, surely, its non-instrumental badness.

The problem, notice, can put in terms of the following idea:

A strategy is additionalist just in case it explains the noninstrumental badness for you of your unpleasant pain in terms of something additional to what constitutes your unpleasant pain.

In FOD's hands, the desire-frustration strategy is additionalist. It says that your unpleasant pain comprises a damage-representing experience and an anti-damage desire, and that its non-instrumental badness additionally requires the desire's frustration-in other words that the given body part actually be damaged. ${ }^{20}$ The problem is simply that this additional state of affairs is not, in truth, required.

In short, the desire and desire-frustration strategies fail not only for SOD but also for FOD. Even so, there is a final desire-based strategy that looks more promising. Let's turn now to it.

\section{FOD and Subjective Desire-Frustration}

A way forward for FOD theorists, it might seem, is to explain the badness of unpleasant pain in terms of subjective rather than real desire-frustration. After all, even if your anti-damage desire in Pain Illusion is not really

${ }^{20}$ For SOD, by contrast, the desire-frustrating circumstance-namely, your having a pain experience-is not additional to but a component of the compound that is the unpleasant pain. frustrated, it seems to you to be. And this, FOD theorists might say, is what is non-instrumentally bad for you. In short, they might pursue the following:

\section{Strategy 4. Subjective desire-frustration}

Explain the badness-for-you of your pain's unpleasantness in terms of two ideas: (a) the unpleasantness of a pain is constituted by an antidamage desire; and (b) subjective desire-frustration is non-instrumentally bad for its subject.

This strategy, in the end, seems to be what Jacobson really has in mind. And it may also be what Aydede and Fulkerson are gesturing at when they talk not only of desire-frustration, but of desire-frustration "as registered by ... incoming sensory information" (forthcoming). ${ }^{21}$ But I shall argue it fails. For, though there are multiple construals of the notion of subjective desire-frustration, none serves FOD's purposes.

Notice, to begin with, that it won't do to construe subjective desire-frustration in terms of a feeling of frustration additional to your pain's unpleasantness caused by the conjunction of your anti-damage desire with a belief that the anti-damage desire is frustrated. For, among other problems, this construal could at best yield an account of the instrumental badness of unpleasant pain, which is not what we're after. ${ }^{22}$

So how else might we construe the subjective desirefrustration? There appear to be two options: we might construe it as believed desire-frustration or as experienced desire-frustration. Start with the first option. It yields the following:

\section{Strategy 4a. Believed desire-frustration}

(i) FOD: Your unpleasant pain comprises a damagerepresenting experience plus an anti-damage desire.

${ }^{21}$ That said, note that the phrase "as registered" is ambiguous in a way I bring out below. ${ }^{22}$ Another problem is that there are (as we're about to see) cases of bad, unpleasant pain where we don't believe our anti-damage desire is frustrated. 
(ii) Your unpleasant pain is non-instrumentally bad for you when and because you believe that desire to be frustrated.

This, alas, also won't do. For suppose that in Pain Illusion you know there is no damage in your foot. Then you won't believe your anti-damage desire to be frustrated. Yet your unpleasant pain will still be noninstrumentally bad for you. To see this, suppose that your pain initially misleads you into thinking there is damage in your foot, but that God subsequently persuades you that there isn't. Surely God thereby eliminates your belief that your desire is frustrated but not the noninstrumental badness of your pain's unpleasantness. In short, this doxastic version of the subjective desire-frustration strategy is implausibly additionalist, requiring for the badness of your unpleasant pain something additional to your unpleasant pain (the believed frustration of your antidamage desire) that is, in truth, not needed.

So might we do better to construe subjective desire-frustration in terms of experienced desire-frustration, where this-let's say-is a matter of wanting the non-obtaining of a circumstance you experience as obtaining? Well, that generates the following version of the strategy:

\section{Strategy $4 b$. Experienced desire-frustration}

(i) FOD: Your unpleasant pain comprises a damagerepresenting experience and an anti-damage desire.

(ii) Your unpleasant pain's non-instrumental badness for you consists in your having an anti-damage desire while experiencing damage as obtaining.

This strategy has advantages. Unlike its predecessor, it can handle Pain Illusion. For Pain Illusion does indeed involve subjective desire frustration. It is also non-additionalist, explaining the badness of your unpleasant pain precisely in terms of what FOD says constitutes it, namely your wanting the non-obtaining of the damage you are experiencing. But, for all this, there is a serious difficulty.

Consider:
Linda, strangely, has a strong intrinsic desire not to be facing unequal parallel lines but, thanks to the MüllerLyer diagram now before her, she experiences that she

Linda, notice, is undergoing experienced desire-frustration in the target sense-she wants the non-obtaining of a circumstance she experiences as obtaining-yet, crucially, her situation need not be bad for her. True, it might be bad for her. She might, for instance, believe the content of her experience, hence believe that her anti-inequality desire is frustrated, hence undergo a feeling of frustration downstream. But though, again, her situation might be bad for her, we can easily imagine that it is not. This is easiest to imagine if we suppose that she doesn't believe the content of her experience, hence doesn't believe her desire is frustrated. Imagine, then, that Linda is au fait with the Müller-Lyer illusion and knows very well that the lines before her are equal lengths even though she experiences them otherwise. Thus construed, her situation surely need not be bad for her at all. And yet it still involves her experiencing desirefrustration in the target sense. So, experiencing desire-frustration in that sense cannot be non-instrumentally bad for a subject, hence cannot be what constitutes the non-instrumental badness of pain's unpleasantness.

None of this is to deny that perceptual experiences can prompt unpleasant feelings even in subjects who disbelieve their contents. Consider:

Ed has a strong intrinsic desire not to be standing on a cliff edge but, thanks to his virtual reality headset, he experiences that he is. Still, he knows he is not.

Even while knowing he is not really on a cliff edge, Ed's virtual-reality experience might cause him to experience fear. But the point is: it also might not. And, in the case in which it doesn't, there plausibly need be nothing bad for him about his situation. Yet his remains a case in which he is undergoing experienced desire-frustration in the relevant sense. 
Hence experienced desire-frustration cannot be what makes your unpleasant pain non-instrumentally bad for you. ${ }^{23}$

In sum, Linda and Ed pose a serious difficulty for strategy $4 \mathrm{~b}$. And notice that the difficulty parallels the difficulty my critics pose for me. For my critics object that what is non-instrumentally bad for you about your unpleasant pain cannot be your representing that your bodily condition is bad for you since in a pair of non-pain cases-namely, believing that your bodily condition is bad for you and being told that it is - the badness of your bodily condition is represented without your subjective situation itself being bad for you (see \$2). Similarly, against these critics, my current point is that what is non-instrumentally bad for you about your unpleasant pain cannot be experienced desire-frustration in the specified sense, since in two non-pain cases-namely, Linda's and Ed'ssubjects experience desire-frustration without their situations needing to be bad for them.

My critics might reply that Linda and Ed's situations are not counterexamples to the non-instrumental badness of experienced desirefrustration in the relevant sense because their situations involve either the wrong kind of experience or the wrong kind of desire or a failure to integrate the two. The first point, focusing on Ed, might be that his virtual-reality experience as of a cliff edge is not a full-blown perceptual experience since it lacks such experience's "phenomenology of encounter" (see $\S 8$ below). But this is implausible. Even while supposing the normative neutrality of Ed's situation, we might imagine Ed saying that, visually, it is for him precisely as though he were standing on a cliff edgethat if he didn't know about the virtual reality headset, he would make an experience-based judgement that he were. ${ }^{24}$ Having to claim he wouldn't

${ }^{23}$ If, as I have been assuming, and as these cases make plausible, Linda and Ed's situations need not be unpleasant despite involving experienced desire-frustration in the sense under discussion, then FOD's problems concern not just the badness of unpleasantness, but unpleasantness itself. For Linda and Ed's cases meet the requirements of a generalised version of FOD, on which undergoing an unpleasant experience of a given sort involves that experience representing $\mathrm{x}$ and being undergone by a subject who desires not- $\mathrm{x}$, and yet-again - their cases need not be unpleasant. See below.

${ }^{24}$ If it helps, substitute for virtual reality your favourite case of perfect hallucination. say this, or that he would be wrong to do so, is a high price to pay to defend the strategy. ${ }^{25}$

The second point is that experienced desire-frustration is bad only when the desire involved is an experiential desire, which Ed's antiedge desire-it might be argued-is not. ${ }^{26}$ But what notion of "experiential desire" is this? The idea might be that the desire involved must have a perceptual-demonstrative content, such as not to be on this cliff edge, by contrast (it might be said) with Ed's merely general desire not to be on cliff edges. But perceptual-demonstrative contents are referentdependent-which is arguably what underlies any intuition we have that they make a normative difference-and FOD theorists cannot restrict their strategy to desires with referent-dependent contents. For this would fail to capture the badness of your unpleasant pain in Pain Illusion, where there was - recall - no state of damage to figure as such a desire's referent. The FOD theorist might of course try to specify some other sense of "experiential" such that the relevant desire's being experiential would make a normative difference. But it is hard to see what sense that might be. Certainly, it won't help to define experiential desires as those that are in the relevant contexts unpleasantness-constituting or those whose subjective frustration is non-instrumentally bad for their subjects. For that would be to build into the notion of an experiential desire what it was supposed to explain. Nor is it easy to see how any other notion of a desire's experientiality would help. For, to the extent that FOD theorists try to explain why subjective desire-frustration is non-instrumentally bad, their explanations tend to appeal not to the relevant desires' experientiality-even if they are thought to have such a feature-but to putative characteristics of desire per se, for instance to the badness of real desire-frustration, or to desire's direction of fit, or to its normative status or evaluative character or reason-giving force. ${ }^{27}$

${ }^{25}$ Similarly, if an attempt is made to save strategy 4a above from the Pain Illusion case by saying a subject whose pain represents an undamaged foot as damaged must believe that the foot is damaged, it should be pointed out that such subjects might sincerely disavow such a belief. ${ }^{26}$ See note 16 above.

${ }^{27}$ Jacobson, for instance, appears to argue from what I've called narrow-scope Humeanism to wide-scope Humeanism and from the latter to the non-instrumental badness of subjective desire-frustration (in review). For their part, Aydede and Fulkerson simply take the badness of phen-desire-frustration (or subjective phen-desire-frustration) as on its face plausible, thereby trading on intuitions about desires per se (see note 16 above). In short, the relevant desires' (or 
The final response under this head is that, even if Linda and Ed's situations involve the right kind of experience and the right kind of desire, they don't involve the right kind of relation between the two. Perhaps it will be said that Ed's anti-edge desire and his edge-representing experience must somehow be disunited in his consciousness. But disunited in what sense? It surely is not the case that we find plausible the possible normative neutrality of Ed's situation only because we are thinking of him as being akin to a split-brain subject (Nagel 1971). One might after all imagine oneself-with unitary consciousness intact-in Ed's situation and still think it needn't involve anything bad for oneself.

In sum, Linda and Ed's cases remain problematic for the experienced desire-frustration strategy as so far understood. But at this point the FOD theorist might be offered a ray of hope. For there is another way of understanding experienced desire-frustration. After all, although it has gone unremarked in the literature, the notion of experiencing the frustration of an anti- $x$ desire is scope-ambiguous, as follows:

Narrow-scope. You desire that $x$ not obtain. And you experience that $x$ does.

Wide-scope. You desire that $x$ not obtain. And you experience that $x$ obtains while you want it not to (or, again, you experience $x$ as unwanted-by-you or as frustrating-a-desire-of-yours). ${ }^{28}$

Thus far we've focused on experienced desire-frustration in the narrowscope sense. That is a matter of wanting the non-obtaining of a circumstance that you experience as obtaining. Wide-scope experienced desire-frustration, by contrast, involves experiencing the circumstance not just as obtaining, but as desire-frustrating. Again, on the wide-scope reading, the desire-frustration itself-not just the putatively frustrating

phen-desires') experientiality appears to be playing no role in FOD theorists' normative explanations.

${ }^{28}$ It is important not to conflate this ambiguity with the distinction between narrow- and widescope Humeanism. Notice too that there is a parallel scope-ambiguity in "believing your antidamage desire to be frustrated" (but this is no help to strategy 4a above, since neither the narrow-scope nor the wide-scope belief is required for the non-instrumental badness of your pain's unpleasantness). circumstance-is actually represented by the experience. Hence FOD theorists might appeal to experienced anti-damage desire-frustration in this wide-scope sense instead, thereby generating the following, final version of the subjective desire-frustration strategy:

\section{Strategy 4c. Experienced desire-frustration (wide-scope)}

(i) FOD: Your unpleasant pain comprises a damagerepresenting experience and an anti-damage desire.

(ii) Your unpleasant pain is non-instrumentally bad for you when and because you experience that the damage is unwanted-by-you, or experience that the damage frustrates a desire of yours.

This final version of the strategy is, I think, the most promising. For it is considerably less clear that Ed and Linda are counterexamples to the necessary badness of experienced desire-frustration in this wide-scope sense. Start with Ed. If he not merely wants the non-obtaining of the cliffedge situation while experiencing that situation to obtain, but further experiences the unwantedness-by-him of that situation, it becomes harder to deny that his subjective state must be bad for him..$^{29}$ As for Linda, recall she experiences the Müller-Lyer lines as unequal and wants the nonobtaining of the represented inequality - not its representation, which is real, but the inequality itself, which she knows not to be. This, I claimed, is not necessarily bad for her. But now suppose her experience further represents her desire's frustration. Suppose, again, it represents the inequality as unwanted-by-her. This arguably shifts our intuitions. It makes the idea that her situation must be bad for her more compelling. In short, wide-scope desire-frustration can seem to be the notion that FOD theorists really need. And as a bonus, it might be argued, it offers another way of unpacking the earlier idea that, for subjective desire-frustration to be bad for a subject, the negative desire must be "experiential" or "united

${ }^{29}$ My claim is not that Ed ever visually represents desire-frustration, but that it is more plausible that his subjective situation is bad for him in a case in which he is in some perceptual or quasiperceptual state representing $X$ as both obtaining and unwanted than if he is merely in the state of wanting not- $X$ while visually (or otherwise) experiencing $X-$ though see below for important tweaks. 
in consciousness" with the subject's perceptual experience. For the sense in which that must be so, it might now be said, is simply that the desireor rather its frustration-must be represented in that experience.

There is, I think, something to all this. Strategy $4 \mathrm{c}$ is indeed more plausible than strategy $4 \mathrm{~b}$. Or, at least, it is once tweaked in response to the following two worries. The first worry is that $4 \mathrm{c}$ is unattractively additionalist given it says that your unpleasant pain involves your wanting the non-occurrence of some damage that you experience as occurring and that this is bad for you only when, additionally, you experience the desire-frustrating-ness of that damage. But FOD theorists might address this by tweaking clause (i) of the strategy - that is, the FOD account itself-so that what the strategy explains in terms of wide-scope experienced desire-frustration is not just the badness of pain's unpleasantness, but the unpleasantness itself. Hence:

Better FOD. Your having an unpleasant pain consists in your having an experience representing an instance of damage as frustrating-a-desire-of-yours.

As desired, Better FOD makes strategy 4c non-additionalist. And it has another advantage. For notice that original FOD doesn't seem to generalise beyond the pain case to other instances of unpleasantness. After all, Linda's situation meets the requirements of a generalised version of FOD-she has an anti- $x$ desire while visually experiencing $x$-yet her situation not only need not be bad for her, it need not be unpleasant either. ${ }^{30}$ Better FOD, by contrast, fairs better. For the idea that her case must be unpleasant seems a good deal more plausible if we stipulate that it involves wide- rather than narrow-scope experienced desire-frustration.

The second worry about $4 \mathrm{c}$ is that wide-scope experienced desirefrustration is too high-level a state-in particular, too demanding a stateto be what your pain's unpleasantness consists in, involving as it does your experiencing a bodily condition as standing in the frustrating relation to a desire of yours. But FOD theorists can address this worry too with a tweak:

${ }^{30}$ See note 23Error! Bookmark not defined.

${ }^{31}$ I have formulated Best FOD in terms of wide- rather than narrow-scope Humeanism. But
Best FOD. Your having an unpleasant pain consists in your having an experience representing an instance of damage as bad for you, where something's instantiating the relevant sort of badness-for-you is a matter of its frustrating an intrinsic desire of yours.

To elaborate: substituting "bad for you" for Better FOD's "frustrating-adesire-of-yours", Best FOD says that your pain's unpleasantness does indeed consist in your interoceptively representing the desire-frustratingness of some bodily damage, but adds that this property, desire-frustratingness, is represented by your pain under the mode of presentation, being bad for you. FOD theorists who have come this far and have Humean sympathies have-it seems to me-no reason to resist this tweak. On the contrary, Best FOD looks like an attractive way to make unpleasant pain less demanding than Better FOD makes it. ${ }^{31}$

In short, Best FOD is an improvement on FOD. And, with Best FOD inserted, I concede that the wide-scope version of the experienced desire frustration strategy offers a considerably more promising way-less vulnerable to the Linda and Ed cases - of invoking anti-damage desires to explain unpleasant pain and its badness. But, for FOD theorists, there is nonetheless one more problem. Best FOD is actually a version of evaluativism! It's a version of the very view that FOD theorists are opposing. After all, Best FOD says that your pain's unpleasantness consists in its representing some bodily damage as bad for you. All it adds to that account is an answer to a question that evaluativists are often asked: "What is the nature of the disvalue that unpleasant pains putatively represent?". Best FOD's answer is that the badness-for-you of your damaged states, represented in your unpleasant pains, is (or is grounded in) the property, being intrinsically unwanted by you. In short, Best FOD is evaluativism plus a desire-theoretic account of the painrepresented badness of the relevant bodily conditions. Some evaluativists, interestingly, have endorsed just such a view. ${ }^{32}$ But of course FOD theorists, who oppose evaluativism, cannot.

${ }^{31}$ I have formulated Best FOD in terms of wide- rather than narrow-scope Humeanism. But there is room for a narrow-scope version too.

${ }^{32}$ Tim Schroeder claims that "displeasure is a perceptual representation of one's desires being on balance less well satisfied ... than expected" (2004: 97) and in correspondence says that this 
In sum, no construal of subjective desire-frustration allows my FOD-theorist critics to accommodate the non-instrumental badness of unpleasant pain. For the badness of your pain depends neither on your believing your anti-damage desire to be frustrated, nor on your merely wanting the non-occurrence of damage while experiencing damage as occurring. And while it may depend on your experiencing the desirefrustrating-ness of that damage, FOD can make best use of that idea only when tweaked in such a way that it becomes a desire-theoretic version of evaluativism.

\section{Strategy 5: the Additionalist Second-Order Desire Strategy}

To this point, my efforts on behalf of evaluativism have been entirely negative, directed at undermining my critics' normative strategies. Let's now turn to what positive strategies I and other evaluativists might pursue instead. To meet the normative condition, recall, evaluativism requires that your interoceptively experiencing a given state of damage as bad for you itself be non-instrumentally bad for you. But how might this be defended against the objections posed in §2? Here, I consider one way; in the final section, I turn to another. following:

A frequently neglected approach evaluativists might take is the

\section{Strategy 5. Additionalist second-order desire strategy}

(i) Explain pain's unpleasantness in terms of a pain experience's evaluative content.

(ii) Hold that, given narrow-scope Humeanism, your unpleasant pain is bad for you when and because you intrinsically desire not to be undergoing unpleasant pain.

Why is this so often neglected? Because, I suspect, it is apt to strike people as either a version of instrumentalism or a SOD strategy. But in fact it's neither. It is not a version of instrumentalism because it doesn't explain

complex desiderative property is thus represented under such a mode of presentation as badfor-me or worse-for-me. the badness of pain's unpleasantness in terms of its bad consequences. Rather, it invokes the same Humean idea that SOD and FOD invoked: that intrinsically wanting the non-obtaining of $x$ renders $x$ noninstrumentally bad for you. Nor is it a SOD strategy. For it does not explain pain's unpleasantness in terms of anti-pain desires. The desires it invokes are not anti-pain desires, but anti-unpleasantness desires; and they are invoked to explain not pain's unpleasantness - which is explained in terms of pain's evaluative content-but the badness of that unpleasantness.

The strategy's appeal to anti-unpleasantness rather than anti-pain desires has two advantages. First, what the strategy claims is made bad by anti-unpleasantness desires is unpleasant pain, not pain per se. Second, unlike anti-pain desires, anti-unpleasantness desires are desires we very obviously have. The strategy also has significant advantages over the FOD strategies. For it is not an approach on which the non-instrumental badness of pain's unpleasantness depends on your body's actually being damaged, or your believing it to be damaged, or your merely wanting it not to be damaged while experiencing that it is. Moreover, it captures the experientiality of the badness of pain's unpleasantness, at least to the following extent: what your anti-unpleasantness desire is directed at is the feeling of your pain's unpleasantness, hence on this strategy that feeling is what is non-instrumentally bad for you.

Notice, however, that while not instrumentalist, strategy 5 is additionalist. To explain pain's unpleasantness and its badness, it invokes distinct explanans: evaluative content, on the one hand, and antiunpleasantness desires, on the other. To put it another way, while the disvalue it explains is non-instrumental, it is not intrinsic. Rather, depending on a desire additional to the unpleasant pain, the badness is extrinsic. Still, this version of additionalism is at least not as implausible as other versions. Recall, for example, FOD's desire-frustration strategy, which made your unpleasant pain non-instrumentally bad for you only when the relevant body part was actually damaged. We objected that God's leaving your unpleasant pain in place while eliminating the damage would not make your pain any less bad for you. But the parallel objection against strategy 5 is less powerful. For it is considerably less obvious that God's leaving your unpleasant pain in place while eliminating your 
intrinsic desire for it not to be occurring would leave your pain's normative status unchanged.

That said, I fear strategy 5's additionalism is ultimately unappealing. Consider:

Coolman has an intensely unpleasant pain, but is indifferent to its unpleasantness in the following sense: he lacks an intrinsic desire for the unpleasantness not to occur, despite being capable of such a desire and reflecting on the matter.

Strangelove has an intensely unpleasant pain, but lacks an intrinsic desire for the unpleasantness not to occur and instead has a strong positive intrinsic desire for its unpleasantness to occur.

What is unappealing is strategy $5^{\prime}$ s commitments in these two cases. It must say that, given Coolman and Strangelove's desires, the intense unpleasantness of their pain is actually not non-instrumentally bad for them, not even slightly, not even pro tanto. Indeed, the intense unpleasantness of Strangelove's pain is-the strategy must say-noninstrumentally good for her. We might well balk at this. There is a strong inclination to say that, on the contrary, the unpleasantness even of Coolman and Strangelove's pain is indeed non-instrumentally bad for them. Relatedly, there is a strong inclination to say that their lack of antiunpleasantness desires, and Strangelove's possession of a prounpleasantness desire, reflect failures of rationality on their part..$^{33}$

Focusing on this last point, friends of strategy 5 might reply that there are real cases of Coolman and Strangelove in which we don't impute irrationality. ${ }^{34}$ Consider asymbolics, the lobotomised, and masochists: asymbolics and the lobotomised say they don't mind their pains, while masochists appear to want theirs, yet arguably we do not say any of them

${ }^{33}$ Those sharing this inclination include Bramble 2013 (213), Goldstein 1980 (354), and Rachels 2000 (201). Even Humeans (in my sense) can allow that intrinsic desires can be irrational or inaccurate in this sense, notice, provided they don't think all disvalue is a matter of negative desire.

${ }^{34}$ There are elements of this reply in Cutter and Tye 2014. thereby manifest irrationality. In reply, however, these cases are quite different from Coolman and Strangelove's. Asymbolics do indeed say they don't mind their pains, but this is because their pains are not unpleasant, not because they lack anti-unpleasantness desires. And what the lobotomised don't mind is arguably not pain's unpleasantness, but its downstream emotional impact-anxiety and the rest-which their lobotomies seem to eliminate. ${ }^{35}$ As for masochists, what they positively want is not unpleasantness per se, but the pleasure that their pain-or perhaps its unpleasantness-somehow generates. So, in the end, none of these cases helps friends of strategy 5 .

Babies might seem a clearer case of humans who lack antiunpleasantness desires, since they seem to lack the introspective sophistication that such desires arguably require. ${ }^{36}$ And arguably we would not say that babies thereby manifest irrationality. But if babies do lack anti-unpleasantness desires, this surely counts against strategy 5, not for it. For it commits the strategy to denying, implausibly, that babies' unpleasant pains are non-instrumentally bad for them

Fellow evaluativists Brian Cutter and Michael Tye offer a different defence of strategy 5 (2014). They claim that anti-unpleasantness desires form "naturally and spontaneously" in properly functioning minds, thanks to such desires being adaptive, motivating subjects as they do to minimise the harmful conditions that tend to cause the unpleasant pains they're directed at $(2014: 427,429)$. Hence, while they concede the intuition that subjects who lack anti-unpleasantness desires are suffering a defect, it is (they argue) a defect not of rationality, but of proper functioning (2014: 428-431).37 However, this reply is less compelling that it might seem. For notice that Cutter and Tye appear to think of the advantageousness of unpleasant pain as resting on the motivationality of the anti-unpleasantness desires they think unpleasant pain naturally triggers. But this might be questioned, especially by evaluativists. For one of the reasons to be an evaluativist is precisely the attractiveness of the

${ }^{35}$ Melzack and Wall report that those lobotomised for chronic pain continue to "complain vociferously about pinprick and mild burn" and say "they still have the 'little' pain, but [that] the 'big' pain, the suffering, the anguish are gone" (2008: 137)

${ }^{36}$ The motivationality of babies' pains is no reason to doubt this; see below.

${ }^{37}$ I've re-cast in terms of "unpleasantness" what Cutter and Tye frame in terms of "painfulness". 
idea that unpleasant pains, conceived as experiences in which damage is represented as bad for oneself, themselves motivate anti-damage actions quite independently of any desires. ${ }^{38}$ Hence Cutter and Tye risk overestimating the survival advantage conferred by anti-unpleasantness desires, hence the degree to which Coolman and Strangelove's defectiveness can be captured in terms of improper functioning.

I do not pretend that any of this amounts to a refutation of strategy 5. But I do think the worry Coolman and Strangelove pose is serious. Suppose, to put it another way, you find yourself intrinsically wanting the non-occurrence in you of beliefs representing given states of bodily damage as bad for you. Intuitively, this differs fundamentally from the case of intrinsically wanting not to be in unpleasant pain. And the difference, surely, is the following. A desire to not believe that a given bodily state is bad for you is not justified by the non-instrumental badnessfor-you of the belief that is its target. For that belief is not noninstrumentally bad for you. By contrast, a desire not to be in unpleasant pain is justified by the non-instrumental badness of its target. Or at least: if any intrinsic desires are thus justified-as Cutter and Tye agree some are - then anti-unpleasantness desires are surely a paradigm case. ${ }^{39}$

To put the point a final way, Strategy 5 implausibly makes the phenomenal character of pain's unpleasantness comparable to the colourrelated character of visual experiences. By this strategy's lights, the only normative difference between pain's unpleasantness and what we might call the "reddish" character of a visual experience of a red tomato is that humans and other animals have evolved typically to want the nonoccurrence of the former but not to want the non-occurrence of the latter Again, in themselves, unpleasantness and reddishness are both normatively neutral. This can seem implausible. While we should certainly accept that a pain might be normatively neutral, as in cases of pain asymbolia, the idea that a pain's unpleasantness might be neutral

${ }_{38}$ See Bain 2013, 2014, 2017, and especially in review.

${ }^{39}$ On justified, intrinsic desires, see Cutter and Tye 429. It is tempting to add that the anti-belief desire (as we might call it) and the anti-unpleasantness desire are alike in respect of the survival advantage they confer. But, in correspondence, Cutter points out that this isn't obvious since the desire not to believe that a given damaged state is bad for oneself might prompt one to engage in maladaptive, motivated reasoning so as to believe, even when false, that the damaged state is not bad for oneself. stretches credulity much further. There is a strong inclination to say that, on the contrary, what is distinctive about unpleasantness vis-à-vis reddishness is precisely the former's inherent disvalue.

In sum, while strategy 5's commitments regarding Coolman and Strangelove might be bullets that evaluativists should bite if there were no other strategy, it behoves us at least to look for an alternative. In the next section, I suggest there is one. ${ }^{40}$

\section{Strategy 6: The Perceptual Strategy}

The normative objection, recall, says that evaluativism explains your pain's unpleasantness in terms of something that is not noninstrumentally bad for you. Evaluativists deny this. We insist that, on the contrary, the experience our explanation invokes - the putative perception of the badness-for-yourself of a given instance of bodily damage-is noninstrumentally bad for you. According to strategy 5, recall, this is so when and because you intrinsically want that experience's non-occurrence. In this section, I sketch an alternative: that such experiences are intrinsically bad for you. Call this the perceptual strategy.

The central idea is that the feeling of pain's unpleasantness, which consists in your seeming to perceive the badness-for-you of a given instance of bodily damage, is bad for you not just non-instrumentally, but intrinsically. This point, happily, is not hostage to the fortunes of Humeanism. And it captures better than its competitors the idea that what is bad about pain's unpleasantness is how it feels. True, strategy 5 can endorse that idea too, but strategy 5 says the feeling is bad for you by dint of your directing at it an additional anti-unpleasantness desire, whereas the perceptual strategy says it is bad for you per se. Hence, crucially, the perceptual strategy allows us to say that the unpleasantness even of Coolman's pain is non-instrumentally bad for him, and that Strangelove's pro-unpleasantness desires are not merely unusual, nor merely maladaptive, but irrational or inaccurate, directed as they are at a feeling

40 My critics too might avail themselves of additional anti-unpleasantness desires to meet the normative condition. For instance, SOD theorists might say that what makes your pain's unpleasantness bad for you is an anti-unpleasantness desire, where that unpleasantness in turn consists in your pain being the object of an anti-pain desire. But they actually don't say this and would face the difficulties above if they did. 
that is antecedently bad for her. ${ }^{41}$ In sum, the perceptual strategy has a great deal to recommend it, provided the critics' doubts can be addressed. But can they?

We might, I suggest, distinguish as many as five doubts. The first centres on the following:

\section{Why-think question}

Why think that your having a perceptual experience representing that your body is in a bad condition is itself bad for you, intrinsically?

This question seems more threatening than it is. For we might simply reply as follows:

\section{The Leibniz's Law argument}

1. Your pain's unpleasantness is bad for you intrinsically.

2. Your pain's unpleasantness is a matter of your undergoing a perceptual experience representing a damaged state of your body as bad for you.

3. Therefore, your undergoing a perceptual experience representing a damaged state of your body as bad for you is bad for you intrinsically.

That is, evaluativists might appeal to the idea that pain's unpleasantness is intrinsically bad-which is intuitive and which underpinned our complaints both about instrumentalism and about strategy 5-and then exploit evaluativism itself (premise 2 above) and Leibniz's Law to argue from that idea to the intrinsic badness of perceiving bodily conditions as being bad for oneself. Of course, circularity would loom if the case for evaluativism exploited this argument's conclusion. But it doesn't. Evaluativists are evaluativists for various reasons - in my case centring on

${ }^{41}$ An unrestricted form of narrow-scope Humeanism would commit us to saying that, if Strangelove intrinsically wants it, the unpleasantness of her pain is to that extent also good for her (pro tanto and non-instrumentally). But that doesn't rule out that Strangelove's prounpleasantness desire is rationally criticisable as an intrinsic desire for something that is antecedently bad for her. the role of unpleasant pain in motivating and rationalising behaviourbut none has argued for the view on the basis of the antecedent obviousness of the badness for a subject of perceiving the badness for himself of his body's damaged states (Bain 2017). Critics are free of course to reject the case for evaluativism, but that is beside the point at this juncture. For the charge being addressed is that evaluativism violates the normative condition, not that evaluativism is unmotivated.

A second worry might be that the Leibniz's Law argument is better taken as a reductio of evaluativism, as an argument to the effect that (2) should be rejected given (1) and the deep implausibility of (3). But in fact not even my critics think that (3) is on its face deeply implausible. Brady, on the contrary, calls it "natural and intuitive" (2015: 406). The normative objection is supposed to be an attempt to show it to be implausible, not a point that presupposes its implausibility.

A third worry is that, even if not clearly false, (3) lacks (1)'s obviousness. Evaluativism cannot be true, the worry goes, if the badness for you of your experiencing the badness of your damaged states is less obvious than the badness for you of your pain's unpleasantness. ${ }^{42}$ But why? After all, the context "... is obviously bad for one" is intensional. Even if it is the case that inserting "your undergoing unpleasant pain" produces a truth whereas inserting "your experiencing a damaged state of your own body as bad for you" produces a falsehood, this doesn't refute evaluativism. Were it a condition on the success of reductions that their explanans be substitutable for their explananda while leaving all platitudes platitudinous, no informative reduction would ever succeed. Consider for comparison an account of redness according to which redness is the disposition of objects to produce "reddish" experiences in normal observers in normal conditions. That account might well be false, but it is not refuted by pointing out that a competent user of "red" might find it unobvious. ${ }^{43}$

${ }^{42}$ This argument is akin to-and as unpromising as-G. E. Moore's notorious open question argument (Moore 1903).

${ }_{43}$ My reply here doesn't jeopardise my objection to the FOD theorist's narrow-scope experienced desire-frustration strategy. For my argument was not that a platitude is eliminated by substituting FOD's account of unpleasant pain for "unpleasant pain" in "unpleasant pain is non-instrumentally bad for its subject", but rather that Linda and Ed's cases are counterexamples to the general idea that narrow-scope experienced desire frustration is bad for its subject. Hence, as noted above, my argument closely parallels my opponents' anti- 
Turning to a fourth point, the critic might protest that, for all this, evaluativists have not yet explained what it is that is bad for you about perceptually experiencing a bodily state of yours as being bad for you. That, I concede, is true. But it is far from obvious that, in this respect, evaluativists are in a worse position than our opponents. For our opponents' too have not explained the putative normative truths to which they appeal. They have not, for instance, explained what is noninstrumentally bad for you about the occurrence of situations whose nonoccurrence you intrinsically want, or about the frustration of your intrinsic desires, or about the subjective frustration of those desires, or about pain's intrusiveness. Now, there may be little to say on these scores, since normative explanation presumably comes to an end somewhere. But if that point is available to my critics, it is available to me too.

Finally, my critics might at this point (as anticipated in \$2) turn to the case of normative belief-or, better, normative judgement-and ask the following:

\section{Normative contrast question}

Consider an unpleasant pain experience of yours. If its intrinsic badness for you consists in its representing a bodily state as bad for you, why isn't your making a judgement with the same content also intrinsically bad for you?

But I think this challenge too can be met. To see this, begin by considering a parallel question:

\section{Phenomenal contrast question}

Consider a visual experience in which a cube looks red to you. If its phenomenal character consists in its

evaluativist point that certain beliefs are counterexamples to the idea that representing bodily damage as bad for you is itself non-instrumentally bad for you. The parallel suggests that evaluativism's normative strategy is at the very least in no worse shape than FOD's. Below, argue in effect that it is in better shape, since (as remarked in $\$ 6$ above; see for instance note 27$)$ my opponents motivate the badness of narrow-scope experienced desire-frustration by appealing to desire per se, making Linda and Ed's cases legitimate counterexamples, whereas the strategy I develop below appeals not to the relevant disvalue's representation per se, but to its perceptual representation. representing a cube as red, why doesn't a judgement with the same content have the same character?

Registering the parallel between these questions helps, I suggest, because there is arguably more than a parallel here. For, faced with the normative contrast question, adherents of the perceptual strategy ought to say the following. What is intrinsically bad for you about your unpleasant pain is its unpleasantness construed as a certain phenomenal feel. And, while evaluativists do indeed explain that feel in terms of the representation of a given bodily state's badness for you, we invoke not just any representations, but perceptual representations. Again, we say that the unpleasant feel consists in the perceptual representation of a state as bad for you. And if at this point the critics ask (à la Brady 2015) how that could make a normative difference-again, how a representation's being perceptual could explain the normative contrast between pains and the corresponding judgements - the reply should be that, if this question does not collapse into an objection already addressed (for instance the worry that we have not explained what is bad for you about the feeling of unpleasantness) then it can only amount to the question how a representation's perceptuality could explain the phenomenal contrast between it and a corresponding judgement. Specifically, it must amount to the question: how could there be a phenomenal difference between an interoceptive experience that a given state of damage is bad for you and a judgement that a given state of damage is bad for you - if the phenomenal character of an experience consists in its possessing the content it possesses? The residual worry behind the normative contrast question, in other words, is simply an interoceptive version of the phenomenal contrast question. Again, the worry about a normative contrast has become a worry about a phenomenal contrast. Hence the worry is neither specifically normative nor specifically about evaluativism. Instead, it is a quite general worry in the philosophy of consciousness - the challenge of finding the feel, as it's sometimes called - which is faced by any view on which an experience's feel consists in its possessing the content it possesses. It is not, then, a worry that evaluativists specifically must address. ${ }^{44}$

${ }^{44}$ Representationalists, who explain experiences' phenomenal character in terms of their possession of content, have tried to "find the feel" in various ways. Some (below) appeal to 
Although the matter could be left here, it might be helpful in closing to register that two of the ways in which the phenomenal contrast between perceptual experience and judgement is sometimes elaborated sit rather well with the idea that a crucial ingredient in the badness of pain's unpleasantness is its perceptuality. Start with the contrast between seeing that there is a red cube before you and judging that there is. On the first elaboration, the visual episode unlike the judgement is an episode in which a red cube's being before you is impressed on your senses. Again, unlike the judgement, the perceptual experience has the role and phenomenology of an episode in which (having opened your eyes and looked in the right direction) an extramental circumstance is foist on your awareness, at least putatively (Evans 1982, McDowell 1994). The second elaboration instead invokes the notions of encounter or contact. By contrast with the judgement, the idea goes, the episode in which it looks to you as though there is a red cube before you involves your encountering the cube and its redness, at least putatively. ${ }^{45}$ Now, these metaphors of impressing and encountering need cashing, of course, but even as they stand they arguably sit nicely with the idea that what underlies the intrinsic badness of pain's unpleasantness is the perceptuality of the representations involved, for the following reasons.

First, I noted above that some of my opponents concede the intuitiveness of the idea that it is intrinsically bad for you to perceptually represent your body's damaged states as bad for you. But notice that the idea becomes more plausible still when expressed in the terms just mooted. For we might now say that what is bad for you about your

experience's distinctive involvement of circumstances being putatively impressed on subjects or subjects putatively encountering things in the world (Evans 1982, McDowell 1994). Others-as alternative to these metaphors or as a way of unpacking them-invoke the idea that perceptual contents involve distinctive modes of presentation or are distinctively fine-grained or "poised" or non-con or non is ceptua (Peacocke 1992, Tye 1995). I shall not explore which approach is best, nor which is compate with representationalism evaluativists should prefer. I shall, however, underscore the generality of the basic idea: that what makes for the phenomenal difference between an unpleasant pain and the corresponding evaluative judgement is whatever makes for the phenomenal difference between experience and judgement in general. It is not something specific to pain unpleasantness, or affect.

${ }^{45}$ Evaluativists who use these terms must disagree with those (e.g. Travis 2004 and Brewer 2006) who think that capturing the relevant idea of encounter requires denying perceptual experiences content. unpleasant pain is not your merely representing damaged states of your body as bad for you, but rather your putatively encountering those states' badness-for-you, or your having their badness-for-you putatively impressed on you. The idea that episodes of this sort should themselves be bad for you is, I suggest, pre-theoretically even more compelling. ${ }^{46}$

Second, when articulated in these terms, the perceptual strategy allows us to capture what might be found attractive in Martínez and Klein's intrusiveness idea, discussed in $\S 3$. For, even while rejecting instrumentalism, it is easy to feel that there was something right about the thought that the badness of unpleasant pain consists in the way pain is, as Klein puts it, an "outside imposition", "impinging" on us (2015b: 182-3, 193). And the perceptual strategy seems to me a good way of capturing just what is right about that idea. For the strategy says that what is bad for us is something's impinging not on our agency, as Klein claims, but on our awareness. In short, the perceptual strategy echoes Klein's talk of imposition and impingement, but in an attractively non-instrumentalist key. ${ }^{47}$

Third, notice that merely imagining yourself "from the inside" undergoing an unpleasant pain need not itself be unpleasant or noninstrumentally bad for you. Notice too that there are indications that the pain experiences of subjects with depersonalisation syndrome, who feel "detached" from their bodies "as if ... living in a dream or movie", arelike the pain experiences of asymbolics-not unpleasant or noninstrumentally bad for them. ${ }^{48}$ The perceptual strategy arguably casts light on both these cases. For even if imagining pain and undergoing depersonalised pain are in some sense sensory experiences, neither involves a putative encounter with reality. Neither, in other words, has the

\footnotetext{
${ }^{46}$ Korsgaard sometimes appears to agree. She says that pain is a "perception that you have a reason to change your [bodily] condition" (1996: 148). And, denying that "value applies reason to change your [bodily] condition" (1996. 148). And, denying that "value applies directly only to conscious states themselves" and that "pleasure and pain merely bring us information about values which are out there in the world", she adds, congenially, that it is bad to perceive something bad partly because of the badness of what one perceives even if that badness isn't real (1996: 155). Curiously, however, other things Korsgaard says sit more comfortably with the SOD strategies or even the intrusiveness account (e.g. 1996: 148, 153-4). ${ }^{47}$ Bennett Helm talks about pain involving "one's body impressing itself on one" (2002: 20, 27). ${ }^{48}$ For the quoted definition, see APA 2000. On depersonalisation and unpleasantness, see Sierra 2009, Klein 2015a, and Dokic in review.
} 
key feature that-on one of our elaborations-the perceptual strategy invokes.

Finally, recall the messenger-shooting version of the normative objection. If experiencing that a given bodily condition is bad for you is bad for you, the worry went, why isn't being told that a given bodily condition is bad for you bad for you? The perceptual strategy provides an answer. Experiencing your body as you do when in pain is a matter of putatively encountering your body and its states; it is not like merely being told about it. ${ }^{49}$

But what about the self-elimination problem, set aside in $\$ 2$ ? Construing unpleasant pains as perceptual representations of the badness of certain bodily states, the worry went, evaluativism is incapable of capturing the idea that pain's unpleasantness itself motivates actions directed at its own elimination-actions, that is, directed at eliminating unpleasant pain. So far, nothing has been said to address this. Happily, however, little needs to be. For evaluativists should simply deny that pain's unpleasantness is self-eliminating. It is true of course that, in pain we perform unpleasantness-directed actions, such as taking painkillers. But, unlike other actions performed when in pain, unpleasantness-directed actions are motivated not by your pain's unpleasantness per se, but only by desires (intrinsic and extrinsic) for that unpleasantness not to be occurring (Bain in review). In short, even if evaluativists cannot meet the self-elimination condition, they can plausibly deny it..$^{50}$

\section{$8080808080 \cos 03030303$}

In conclusion, I have made three key claims. First, accounts of pain's unpleasantness must meet the normative condition; instrumentalism will not do. Second, those who argue that evaluativism cannot meet the normative condition advance desire-theoretic accounts of pain's unpleasantness that themselves fail to meet it. Finally, evaluativism actually can meet the condition, in either of two ways. Evaluativists can

${ }^{49}$ This may suggest it is better for the perceptual strategy to construe perceptions as encounters than impressings -though even the impressings model can be elaborated such that acts of testimony don't fit it (McDowell 1994).

${ }^{50}$ Arguably, notice, even SOD fails to meet the self-elimination condition, invoking as it does anti-pain rather than anti-unpleasantness desires. appeal to anti-unpleasantness desires, as per strategy 5. Or, to better accommodate our intuitions about Coolman and Strangelove, and to capture more fully the experientiality-indeed, the perceptuality-of the badness of pain's unpleasantness, evaluativists can deploy the perceptual strategy. ${ }^{51}$

David Bain, University of Glasgow

\section{REFERENCES}

APA 2000: Diagnostic and Statistical Manual of Mental Disorders: DSM-IVTR. Washington, DC: American Psychological Association.

Armstrong, D.M. 1962, Bodily Sensations (London: Routledge and Kegan Paul).

Bain, D. 2013. 'What makes pains unpleasant?' Philosophical Studies 166: S69-89.

Bain, D. 2014. 'Pains That Don't Hurt'. Australasian Journal of Philosophy 92:2, 305-320

Bain, D. 2017. 'Evaluativist Accounts of Pain's Unpleasantness'. In: Corns, J. Routledge Handbook of Philosophy of Pain.

Bain, D. In review. Pain and Action

Aydede, M. 2014. 'How to Unify Theories of Sensory Pleasure: An Adverbialist Proposal'. Review of Philosophy and Psychology 5: 119-133.

${ }^{51}$ I wrote this paper while Principal Investigator of the Value of Suffering Project, funded by the John Templeton Foundation. I am grateful for comments and discussion to Murat Aydede, Micher Michael Brady, Jennifer Corns, Robert Cowan, Garrett Cullty, Brian Cutter, Frédérique de Vignemont, Chris Heathwood, Colin Klein, Neil McDonnell, Fiona Macpherson, Manolo Martínez, Tom McClelland, Abraham Sapién-Córdoba, Mark Schroeder, Tim Schroeder, Jon Simon, Jonathan Way, and an anonymous referee; and also to audiences at the Autonomous University of Barcelona, University of Cardiff, University of Edinburgh, University of Geneva, University of Glasgow, Maquarie University's CAVE Centre, Hebrew University of Jerusalem, Autonomous National University of Mexico, and University of Zürich. Special thanks are due to Hilla Jacobson for extensive discussion and for the fascinating paper (in review) which prompted a great deal of the above. 
Aydede, M. and M. Fulkerson. Forthcoming. 'Reasons and Theories of Sensory Affect'. In: Bain, D., Brady, M. and Corns, J. The Nature of Pain.

Bastian, B. and Siri Leknes. 2014. 'The Benefits of Pain'. Review of Philosophy and Psychology. 5:57-70

Brady, M. S. Forthcoming-a. 'Painfulness, Desire, and the Euthyphro Problem', American Philosophical Quarterly.

Brady, M. S. Forthcoming-b. Suffering and Virtue. Oxford: Oxford University Press.

Brady, M. 2015. 'Feeling Bad and Seeing Bad'. Dialectica 69(3): 403-416.

Bramble, B. 2013. 'The Distinctive Feeling Theory of Pleasure'. Philosophical Studies 162: 201-217

Brewer, B. 2006. 'Perception and Content'. European Journal of Philosophy 14: $165-181$.

Cullity, G. 1997. 'Practical Theory'. In: Garrett Cullity and Berys Gaut, Ethics and Practical Reason. Oxford: Clarendon Press.

Cutter, B. and M. Tye. 2011. 'Tracking Representationalism and the Painfulness of Pain'. Philosophical Issues 21: 90-109.

Cutter, B. and M. Tye. 2014. 'Pains and Reasons: Why it Is Rational to Kill the Messenger'. Philosophical Quarterly 64(256): 423-433.

Dokic, J. In review. 'The Role of Noetic Feelings in Sensory Substitution'.

Evans, G. 1982. Varieties of Reference. Oxford: Oxford University Press.

Foot, P. 1972. 'Morality as a System of Hypothetical Imperatives', Philosophical Review 81: 3, 305-316.

Goldstein, I. 1980. 'Why People Prefer Pleasure to Pain'. Philosophy, 55: 349-362.

Grahek, N. 2007. Feeling pain and being in pain, 2nd ed. Cambridge: MIT Press.

Heathwood, C. 2007. 'The Reduction of Sensory Pleasure to Desire'. Philosophical Studies 133: 23-44

Helm, B. 2002. 'Felt Evaluations: A Theory of Pleasure and Pain', American Philosophical Quarterly, 39, 1, 13-30.

Jacobson, H. 2013. 'Killing the Messenger: Representationalism and the Painfulness of Pain'. Philosophical Quarterly 63(252): 509-519.

Jacobson, H. 2014. Phenomenal Consciousness: A Conative-Evaluative Point of View. Saarbrücken: Scholars' Press.
Jacobson, H. In review. 'Not Only a Messenger: Towards an AttitudinalRepresentational Theory of Pain'.

Klein, C. 2015a. 'What Pain Asymbolia Really Shows'. Mind 124(494): 493-516.

Klein, C. 2015b. What the Body Commands. Cambridge, Mass.: MIT.

Korsgaard, C. 1996. Sources of Normativity. Cambridge: Cambridge University Press.

Martinez, M. 2011. 'Imperative Content and the Painfulness of Pain', Phenomenology and the Cognitive Sciences, 10, 67-90.

Martinez, M. 2015. 'Pains as Reasons'. Philosophical Studies. 172: 9, 22612274

McDowell, J. 1994. Mind and World. Cambridge, MA: Harvard University Press.

McGinn, C. 1982. The Character of Mind. Oxford: Oxford University Press.

Melzack, R. and P. D. Wall 2008. Challenge of Pain ( $2^{\text {nd }}$ edition). London: Penguin Books.

Moore, G. E. 1903. Principia Ethica, New York: Cambridge University Press.

Nagel, T. 1971. 'Brain Bisection and Unity of Consciousness'. Synthese 22: 396-413.

Peacocke, C. 1992. A Study of Concepts. Cambridge, Mass.: MIT Press.

Rachels, S. 2000. 'Is Unpleasantness Intrinsic to Unpleasant Experiences?' Philosophical Studies 99: 187-210.

Railton, P. 2003. Facts, Values, and Norms: Essays toward a morality of consequence. New York: Cambridge University Press.

Rorty, R. 1980. Philosophy and the Mirror of Nature. Oxford: Basil Blackwell.

Schiffer, S. 1976. 'A Paradox of Desire', American Philosophical Quarterly, 13, 195-203.

Schroeder, M. 2007. Slave of the Passions. Oxford: Oxford University Press.

Schroeder, M. 2013. 'Scope for Rational Autonomy'. Philosophical Issues 23: $297-310$ 
Schroeder, M. 2015. 'Hypothetical Imperatives, Scope, and Jurisdiction.' In: Robert Johnson and Mark Timmons, Reason, Value, and Respect. Oxford: Oxford University Press.

Schroeder, T. 2004. Three Faces of Desire. New York: Oxford University Press.

Sierra, M. 2009. Depersonalization: A New Look at a Neglected Syndrome. New York: Cambridge University Press.

Smith, M. 1994. The Moral Problem. Oxford: Oxford University Press.

Travis, C. 2004. 'The Silence of the Senses'. Mind 113(449): 57-94.

Tye, M. 1995. Ten Problems of Consciousness (Cambridge, Mass.: MIT Press). 